\title{
The new oral anticoagulants
}

\author{
F.W.A. Verheugt
}

In patients with nonvalvular atrial fibrillation oral anticoagulation with the vitamin $\mathrm{K}$ antagonists acenocoumarol, phenprocoumon and warfarin reduces the risk of stroke by more than $60 \%$, whereas single or double antiplatelet therapy is much less effective and sometimes associated with a similar bleeding risk as vitamin $\mathrm{K}$ antagonists. Besides bleeding, INR monitoring and high interindividual variability remain the largest drawbacks of vitamin $\mathrm{K}$ antagonists. In the last decade oral agents have been developed that directly block the activity of thrombin (factor IIa), as well as drugs that directly inhibit activated factor $\mathrm{X}(\mathrm{Xa})$, which is the first protein in the final common pathway to the activation of thrombin. These agents have huge advantages in that they do not need monitoring and have a fast onset and offset of action. This survey addresses the role of classical and modern anticoagulation in stroke prevention in atrial fibrillation. (Neth Heart J 2010;18:314-8.)

Keywords: Anticoagulants; Administration, Oral; Atrial Fibrillation; Warfarin; Drug Discovery; Stroke

$\mathbf{T}$ he yearly incidence of stroke in patients with atrial fibrillation is about $5 \%,{ }^{1}$ which is five times higher than in comparable populations in sinus rhythm. The stroke risk largely depends on the underlying heart disease. In 'lone' atrial fibrillation (absence of heart disease) the stroke risk is only $0.5 \%$ per year, ${ }^{2}$ whereas in atrial fibrillation associated with rheumatic valvular heart disease such as mitral valve stenosis it is very high.

F.W.A. Verheugt

Department of Cardiology, Onze Lieve Vrouwe Gasthuis, Amsterdam, the Netherlands

Correspondence to: F.W.A. Verheugt

Department of Cardiology, Onze Lieve Vrouwe Gasthuis, PO

Box 95500, $1090 \mathrm{HM}$ Amsterdam, the Netherlands

E-mail f.w.a.verheugt@olvg.nl

\section{The classical anticoagulants}

The coagulation cascade is a complex system that can be activated by an intrinsic pathway (blood stasis and contact activation) or an extrinsic pathway (exposed tissue after vascular damage). The final common pathway from these two potential stimuli starts with the activation of the plasma factor $\mathrm{X}$ into activated factor Xa (figure 1). Through activation of factor $\mathrm{V}$ factor II (prothrombin) is activated to thrombin, the aggressive enzyme splitting fibrinogen into fibrin, which is the matrix of blood clots. The coagulation system is a real cascade. One molecule of factor Xa induces the formation of 50 to 1000 thrombin molecules. Factor Xa and thrombin are counteracted by the naturally occurring antithrombin-III.

The parenteral anticoagulants heparin, low-molecular-weight heparins and pentasaccharide stimulate the activity of antithrombin-III and, therefore, are indirect inhibitors of factor Xa and thrombin, where heparin has the lowest and pentasaccharide the highest anti-Xa activity. A parenteral Xa inhibitor is otamixaban, which is currently under investigation in ischaemic heart disease. There are several parenteral direct thrombin inhibitors available: recombinant hirudin, bivalirudin and argatroban.

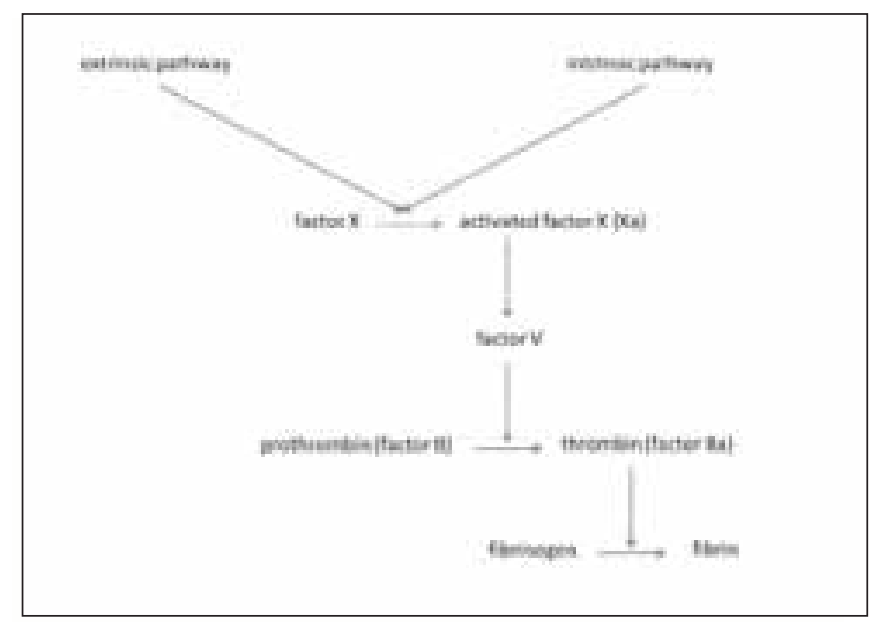

Figure 1. Simplified schema of the coagulation cascade. 
These agents are also used in the management of ischaemic heart disease.

So far, the only available oral anticoagulants are the coumarin derivatives. These compounds block the vitamin $\mathrm{K}$ dependent liver production of the plasma coagulation factors II, VII, IX and X. They are usually called vitamin $\mathrm{K}$ antagonists and have a relatively narrow therapeutic window, which is due to dose-response, food and genetic variation. Therefore, vitamin $\mathrm{K}$ antagonists require close monitoring: overdosing may result in life-threatening bleeding and underdosing in inefficacy. Major improvements in the monitoring of oral anticoagulation have been made. An international and uniform laboratory standard of the intensity of anticoagulation has been introduced: the International Normalised Ratio (INR) replacing the non-standardised prothrombin time and Quick tests. Nevertheless monitoring remains cumbersome and less than two-thirds of patients on chronic therapy with vitamin $\mathrm{K}$ antagonists are within the therapeutic window.

Warfarin therapy is the cornerstone in the prevention of thromboembolism in patients with atrial fibrillation. Stroke in patients with persistent or permanent non-valvular atrial fibrillation can be reduced by $67 \%$ by the use of oral anticoagulants. ${ }^{3}$ Severe bleeding with warfarin is seen in one out of 100 patients per year, which is double the risk of stroke in lone atrial fibrillation. Therefore, anticoagulation is only indicated in atrial fibrillation patients with a stroke risk that exceeds the risk of severe bleeding. Risk stratification for stroke in atrial fibrillation is now widely accepted with the so called CHADS 2 score, ${ }^{4}$ where patients with a score of 1 and higher are candidates for oral anticoagulation (table 1). The optimal target INR for patients with artificial heart valves and those with atrial fibrillation has now been well established. ${ }^{5}$ Also for patients who survived myocardial infarction routine anticoagulation can be of help and has shown to be superior to aspirin alone in the prevention of recurrent myocardial infarction and stroke. ${ }^{6,7}$ Also the combination of oral anticoagulation and aspirin following myocardial infarction proved to be superior to aspirin alone in those trials. Yet, the use of oral anticoagulation is associated with the risk of severe and even fatal bleeding.

Not only anticoagulants but also antiplatelet therapy may reduce the incidence of stroke in atrial fibrillation when compared with placebo, but in direct comparisons with warfarin it is much less effective. ${ }^{3}$ Although simple in use and very cost-effective, aspirin is also associated with severe bleeding. ${ }^{8}$ Aspirin in combination with clopidogrel is related to even more bleeding ${ }^{9}$ and sometimes fatal bleeding. ${ }^{10}$ Furthermore, in atrial fibrillation the combination of aspirin and clopidogrel is clearly not an alternative to oral anticoagulation, as shown in the large ACTIVE-W trial ${ }^{11}$ comparing warfarin
Table 1. $\mathrm{CHADS}_{2}$ score points for prediction of stroke in atrial fibrillation. ${ }^{4}$

\section{Risk factor}

Age over 75 years

Previous stroke/TIA

Hypertension

Symptoms or signs of LV dysfunction

Diabetes mellitus

\section{Points}

1

2

1

1

1 with the combination of aspirin and clopidogrel in the prevention of thromboembolism. In that trial bleeding with dual antiplatelet therapy was similar to warfarin if not more. ${ }^{11}$ Physicians should realise that the combination aspirin/clopidogrel may have the same bleeding potential as warfarin. ${ }^{12}$

Many physicians are reluctant to prescribe warfarin to the elderly patient with atrial fibrillation because of the risk of bleeding, and many are convinced that aspirin is a wise and acceptable alternative. This was established in a Dutch trial in the primary care of patients with atrial fibrillation showing equal efficacy of warfarin and aspirin. ${ }^{13}$ However, comparative data in the very elderly (over 75 years) are rather scarce. ${ }^{14}$ Therefore, the recently published BAFTA (Birmingham Atrial Fibrillation Treatment of the Aged) trial was very welcome.

In BAFTA 973 patients over the age of 75 with atrial fibrillation were randomised to warfarin (target INR 2-3), or aspirin $75 \mathrm{mg}$ daily. ${ }^{15}$ Fatal or disabling stroke, or clinically significant arterial embolism was seen $1.8 \%$ / year with warfarin versus 3.8\% / year with aspirin (relative risk $0.48,95 \%$ CI 0.28 to $0.80, p=0.003$ ). The number of very elderly patients to treat to prevent one endpoint per year was 50. Major bleeding was similar amongst the two treatment groups including the risk of intracranial haemorrhage. These data must be reassuring for physicians taking care of the elderly with atrial fibrillation and prescribing them warfarin. If there are no clear contraindications to warfarin (gastrointestinal ulceration, dementia or syncopal attacks) warfarin is an excellent therapy for this group of patients but their bleeding risk will probably be higher than in BAFTA. If there is an expected lack of cooperation by the patient, aspirin can be a good alternative. Even in BAFTA the bleeding rate in the elderly was below $4 \%$ per year on aspirin with an acceptable risk of stroke.

Nevertheless, rather than antiplatelet therapy better anticoagulant medication should be sought for.

\section{New oral anticoagulants}

In the past decade several oral direct inhibitors of thrombin and of factor Xa have been developed (table 2). They proved to be specific antagonists 
Table 2. The new oral anticoagulants.

\begin{tabular}{|c|c|c|c|c|c|}
\hline \multirow{2}{*}{$\begin{array}{l}\text { Class } \\
\text { Anti-Ila (antithrombin) }\end{array}$} & \multirow{2}{*}{$\begin{array}{l}\text { Name } \\
\text { dabigatran }\end{array}$} & \multirow{2}{*}{$\begin{array}{l}\text { Manufacturer } \\
\text { Boehringer-Ingelheim }\end{array}$} & \multirow{2}{*}{$\begin{array}{l}\mathbf{T} 1 / 2(\mathbf{h}) \\
7-9\end{array}$} & \multicolumn{2}{|c|}{ Excretion } \\
\hline & & & & 80\% kidney & $20 \%$ liver \\
\hline \multirow[t]{5}{*}{ Anti-Xa } & apixaban & Bristol-Myer-Squibb & $8-15$ & $21 \%$ kidney & $78 \%$ liver \\
\hline & rivaroxaban & Bayer & 9-12 & 33\% kidney & $66 \%$ liver \\
\hline & edoxaban & Daiichi-Sankyo & $8-10$ & $35 \%$ kidney & $65 \%$ liver \\
\hline & LY-517717 & Eli Lilly & 24 & & 100\% liver \\
\hline & YM-150 & Astellas & $14-20$ & $25 \%$ kidney & $75 \%$ liver \\
\hline
\end{tabular}

Table 3. Advantages and disadvantages of the new oral anticoagulants relative to warfarin.

\section{Class}

Oral Ila/Xa blockers

Vitamin-K antagonists

\section{Advantages}

No monitoring

Fast onset of action

Fast offset of action (in case of bleeding/surgery)

Proven high effectiveness

Therapeutic window established

Antidote established

Long action (low thrombosis risk with poor compliance)

\section{Disadvantages}

Efficacy not yet firmly established

Some agents need twice daily dosing

Short duration of action (thrombosis risk with poor compliance)

Antidote not established

No monitoring (in case of bleeding/surgery Cost

Monitoring of INR

Drug interaction

Food interaction

Slow onset of action

High bleeding risk

Table 4. Phase III trials with new oral anticoagulants in atrial fibrillation.

\begin{tabular}{lllll}
\hline Class & Name (dosing) & Comparator & Design & Trial \\
Anti-lla (antithrombin) & dabigatran (bid) & Warfarin (clinic) & Open for warfarin & RE-LY \\
Anti-Xa & apixaban (bid) & Warfarin (point of care) & Double-blind & ARISTOTLE \\
& rivaroxaban (qd) & Warfarin (point of care) & Double-blind & ROCKET-AF \\
& edoxaban (qd) & Warfarin (point of care) & Double-blind & ENGAGE-AF TIMI 48 \\
bid=twice daily, qd=once daily. & & & &
\end{tabular}

and show a dose-efficacy relationship. A major advantage is that there does not seem to be any drug tolerance and food interaction, and monitoring is not necessary with these agents. They have a fast onset of activity and a relatively short duration of action, which in case of bleeding is another advantage over vitamin $\mathrm{K}$ antagonists. On the other hand, some agents need twice daily dosing and the fast offset of action may be problematic in case of poor compliance, e.g. when two or three doses in sequence are not taken by the patient. This disadvantage is not seen with warfarin, or the antiplate- let agents aspirin and clopidogrel, which all have a very slow offset of action. Furthermore, an antidote algorithm for the novel oral anticoagulants has not been developed yet, where this is well established for warfarin.

The advantages and disadvantages of the novel oral anticoagulants relative to vitamin $\mathrm{K}$ antagonists are summarised in table 3 .

\section{The trials}

The direct oral thrombin (factor IIa) inhibitor ximelagatran is as effective as warfarin and reduces 
major bleeding ${ }^{16,17}$ but the drug is associated with liver toxicity, which withholds its approval and further marketing. Another direct oral thrombin blocker dabigatran is currently under evaluation in comparison with warfarin in a huge phase III (RE-LY) trial in atrial fibrillation (table 4). Finally, oral direct factor Xa blockers are currently available and are effective in deep vein thrombosis and pulmonary embolism. ${ }^{18-22}$ Rivaroxaban, apixaban and edoxaban are also under trial for stroke prevention in atrial fibrillation. Besides efficacy and cost-effectiveness bleeding is a major safety endpoint of these agents when compared with warfarin.

As shown in table 4 the running trials differ in design in that the warfarin treatment in RE-LY is open label and double-blind in the other trials, by which INR is measured at the point of care and sham INRs are computer-generated for the patients randomised to the new agent. Double-blind controlled trials are the highest standard of quality in evidence-based medicine and also in the case of INR monitored trials blinding is feasible and successful. ${ }^{17}$ Open-label studies have the serious shortcoming of treatment bias. In case of bleeding with open-label warfarin, physicians will react differently than in a bleeding case with a drug that could be either an experimental short-acting new oral anticoagulant or warfarin. Therefore, the design of RE-LY makes its outcome less reliable when positive for the new agent. A good example of this is the differential results of the studies where ximelagatran was compared with warfarin in stroke prevention for atrial fibrillation. SPORTIF-III was an open-label trial and stroke prevention tended to be better with ximelagatran than with warfarin, ${ }^{16}$ but in SPORTIF-V with its double-blind design it was the other way around. ${ }^{17}$ The ximelagatran arms of both trials had an almost identical outcome making both studies highly comparable in baseline features. Although complex to perform, trials of new oral anticoagulants must be double-blind in design, such as ENGAGE-AF-TIMI 48 (edoxaban), ARISTOTLE (apixaban) and ROCKET-AF (rivaroxaban), as were the trials in evidence-based medicine we use nowadays and that have been tested double-blind in the 1990s, such as those on $\beta$-blockers, aspirin, statins and ACE inhibitors.

By design the trials will include both warfarinexperienced and warfarin-naive patients and by stratification the results on both efficacy and bleeding will be analysed. By this stratification post-hoc analyses on this topic can be circumvented, because this was heavily criticised in the ACTIVE-W trial. ${ }^{23}$

\section{Conclusion}

From the current trials it will become clear, whether oral direct inhibition of the major haemostatic proteins factor IIa or factor Xa will be as effective as warfarin in stroke prevention of atrial fibrillation with a safety profile which may be more favourable than warfarin. If so, the lack of monitoring will be the major reason for many physicians to switch from warfarin to the new agents and to put firstcomers with atrial fibrillation without anticoagulants on them right away.

\section{Conflict of interest}

I have received departmental research funding and consultancy fees from Sanofi-Aventis and BMS/ Pfizer as well as speaker honoraria from AstraZeneca.

\section{References}

1 Wolf PA, Abbott RD, Kannel WB. Atrial fibrillation: a major contributor to stroke. The Framingham study. Arch Intern Med. 1987;147:1561-4.

2 Kopecky SL, Gersh BJ, McGoon MD, et al. The natural history of lone atrial fibrillation: A population-based study over three decades. N Engl J Med. 1987;317:669-74.

3 Lip GY, Hart RG, Conway DS. Antithrombotic therapy for atrial fibrillation.BMJ. 2002;325:1022-5.

4 Gage BF, Waterman AD, Shannon W, Boechler M, Rich MW, Radford MJ. Validation of clinical classification schemes for predicting stroke: results from the National Registry of Atrial Fibrillation. JAMA. 2001;285:2864-70.

5 De Caterina R, Husted S, Wallentin, L, et al. Anticoagulants in heart disease: current status and perspectives. Eur Heart J. 2007;28:880-913.

6 Van Es RF, Jonker JJC, Verheugt FWA, Deckers JW, Grobbee DE. Aspirin and coumadin after acute coronary syndromes (the ASPECT-2 study): a randomised controlled trial. Lancet. 2002:360:109-13.

7 Hurlen M, Abdelnoor M, Smith P, Erikssen J, Arnesen H. Warfarin, aspirin, or both after myocardial infarction. N Engl J Med. 2002;347:969-74.

8 Hayden M, Pignone M, Phillips C, Mulrow C. Aspirin for the primary prevention of cardiovascular events: a summary of the evidence for the U.S. Preventive Services Task Force. Ann Intern Med. 2002;136:161-72.

9 CURE Investigators. Effect of clopidogrel in addition to aspirin in patients with acute coronary syndromes without ST-segment elevation. N Engl J Med. 2001;345:494-502.

10 Bhatt DL, Fox KAA, Hacke W, et al. Clopidogrel and aspirin versus aspirin alone for the prevention of atherothrombotic events. N Engl J Med. 2006;354:1706-17.

11 ACTIVE Investigators. Randomized controlled trial of clopidogrel plus aspirin versus oral anticoagulation in patients with atrial fibrillation: The Atrial Fibrillation Clopidogrel Trial with Irbesartan for Prevention of Vascular Events (ACTIVE). Lancet. 2006;367:1903-12.

12 Verheugt FWA. Good old warfarin for stroke prevention in atrial fibrillation. Lancet. 2006;367:1877-8.

13 Hellemons BSP, Langenberg M, Lodder J, et al. Primary prevention of arterial thromboembolism in non-rheumatic atrial fibrillation in primary care: randomised controlled trial comparing two intensities of coumarin with aspirin. BMJ. 1999;319:175-8.

14 Garcia D, Hylek E. Stroke prevention in elderly patients with atrial fibrillation. Lancet. 2007;370:460-1.

15 Mant J, Hobbs R, Fletcher K, et al. Warfarin versus aspirin for stroke prevention in an elderly community population with atrial fibrillation (the Birmingham Atrial Fibrillation Treatment of the Aged Study, BAFTA): a randomised controlled trial. Lancet. 2007;370:493-503.

16 SPORTIF-III Investigators. Ximelagatran versus warfarin for stroke prevention in patients with nonvalvular atrial fibrillation (SPORTIF-III): randomised controlled trial. Lancet.2003;362:1691-8.

17 Albers GW, Diener HC, Frison L, et al Ximelagatran vs warfarin for stroke prevention in patients with nonvalvular atrial fibrillation: a randomized trial. JAMA. 2005;293:690-8. 
18 Agnelli G, Gallus A, Goldhaber SZ, et al. Treatment of proximal deep-vein thrombosis with the oral direct factor Xa inhibitor rivaroxaban (BAY 59-7939): the ODIXa-DVT (Oral Direct Factor Xa Inhibitor BAY 59-7939 in Patients With Acute Symptomatic Deep-Vein Thrombosis) study. Circulation. 2007;116:180-7.

19 Eriksson BI, Borris LC, Friedman RJ, et al. Rivaroxaban versus enoxaparin for thromboprophylaxis after hip arthroplasty. N Engl J Med. 2008;358:2765-75.

20 Kakkar AK, Brenner B, Dahl OE, et al. Extended duration rivaroxaban versus short-term enoxaparin for the prevention of venous thromboembolism after total hip arthroplasty: a doubleblind, randomized controlled trial. Lancet. 2008;372:31-9.

21 Lassen MR, Ageno W, Borris LC, et al. Rivaroxaban versus enoxaparin for thromboprophylaxis after total knee arthroplasty. N Engl J Med. 2008;358:2776-86

22 Turpie AGG, Lassen MR, Davidson BL, et al. Rivaroxaban versus enoxaparin for thromboprophylaxis after total knee arthroplasty (RECORD-4). Lancet. 2009;373:1673-80.

23 Verheugt FWA. Good old warfarin for stroke prevention in atrial fibrillation. Lancet. 2006;367:1877-8. 